\title{
Tipe Ruang Kreatif di Bandung dan Konteks Pendukungnya
}

\section{Types of Creative Spaces in Bandung and Their Supporting Contexts}

\author{
Ihsan Maulanar Robbany ${ }^{1}$, Josephin Maria Prastika Atidipta ${ }^{1}$, Shabrina Amalia Ihsanti ${ }^{1}$, \\ Vadya Dzauqiah"1, Agus Suharjono Ekomadyo' \\ ${ }^{1}$ Institiut Teknologi Bandung, Bandung Indonesia. \\ imrobbany@gmail.com, josephinpastika@gmail.com, shabrinaaihsanti@gmail.com, dzauqiahvadya@gmail.com, \\ aekomadyo00@gmail.com
}

doi.org/10.29080/eija.v5i2.779

\begin{abstract}
The creative class is a group of people who utilize their creative thinking as a way to solve problems by creating innovations. The development of the creative class in the urban regions of the world results in a term called the creative city. Inside a creative city, the activity of the creative class establishes the needs for spaces that can accommodate their activities. Bandung, one of a creative city in Indonesia, has a lot of creative spaces. This research aims to map the types of creative spaces in Bandung, including their relationship with their contexts. This is achieved through the study of three cases, Kompleks Gudang Selatan, Lo.Ka.Si Coffee \& Spaces, and Bandung Creative Hub. The mapping of creative spaces is done using the quantitative and qualitative scoring systems through observation, user interviews, and management interviews. Study about contexts is done using interviews and literature studies. The result of this research shows that those 3 cases, as creative spaces, are dominated by presentation space. This is supported by factors in their firm aspects. Moreover, it is found that the creative industry in Bandung is currently still oriented at presentation activities.
\end{abstract}

Keywords: creative space, creative space types, supporting context

\begin{abstract}
Abstrak: Kelas kreatif merupakan orang-orang yang menggunakan pemikiran kreatifnya untuk memecahkan permasalahan melalui inovasi-inovasi. Aktivitas kelas kreatif memicu kebutuhan akan ruang yang dapat mengakomodasi kegiatan mereka. Kota Bandung adalah salah satu contoh kota kreatif sehingga memiliki banyak ruang kreatif. Penelitian ini bertujuan memetakan tipe-tipe ruang kreatif di Kota Bandung beserta hubungan dengan konteksnya melalui tiga studi kasus yakni Kompleks Gudang Selatan, Lo.Ka.Si Coffee \& Space, dan Bandung Creative Hub. Pemetaan ruang kreatif dilakukan melalui penilaian kuantitatif dan penilaian kualitatif melalui observasi dan wawancara pengelola serta pengguna. Sedangkan, studi mengenai konteks kasus dilakukan lewat wawancara dan studi pustaka. Hasil penelitian menunjukkan bahwa ketiga kasus tersebut merupakan ruang kreatif yang didominasi oleh ruang presentasi. Hal ini banyak didukung oleh faktor-faktor pada aspek kelembagaan. Selain itu, ditemukan bahwa industri kreatif di Bandung masih berorientasi pada kegiatan presentasi.
\end{abstract}

Kata Kunci: ruang kreatif, tipe ruang kreatif, konteks pendukung

\section{PENDAHULUAN}

Saat ini banyak dunia kerja dihidupkan oleh keberadaan orang-orang kreatif yang ternyata punya karakter yang khas. Oleh Florida (2014) mereka disebut sebagai "Kelas Kreatif", yaitu orang-orang yang menggunakan pemikiran kreatifnya untuk memecahkan permasalahan melalui berbagai inovasi. Kelas kreatif terdiri dari peneliti, desainer, insinyur, seniman, arsitek, guru, pemimpin bisnis, pemimpin organisasi sektor publik, dan sebagainya. Ketika keberadaan mereka secara signifikan mempengaruhi kehidupan kota, maka muncul gerakan kota-kreatif, yaitu bagaimana kota bisa menjadi wadah yang kondusif bagi kelas kreatif untuk bekerja dan berkarya.

Dalam suatu kota kreatif, aktivitas para kelas kreatif memicu kebutuhan akan ruang yang dapat mengakomodasi kegiatan mereka. Hal ini memunculkan tipologi ruangan baru bernama ruang kreatif. Penelitian Thoring, Luippold, \& Ueller, (2012) memetakan ruang kreatif ke dalam 5 tipe berdasarkan kegiatan yang diakomodasinya. Tipe pertama adalah ruang personal (personal space) untuk perenungan dan meditasi. Tipe kedua adalah ruang kolaborasi (collaboration space), yang memfasilitasi interaksi dan 
kerjasama. Berikutnya adalah ruang cipta (maker space), sebagai tempat eksperimen dan perwujudan karya secara fisik. Tipe keempat adalah ruang presentasi (ruang presentasi) sebagai sarana publikasi karya. Tipe terakhir adalah ruang perantara (intermission space) seperti ruang istirahat, koridor, dan taman. Klasifikasi tipe ruang kreatif tersebut disusun sejalan dengan temuan-temuan dan teori-teori yang telah ada (Thoring, Desmet, \& Badke-Schaub, 2019). Sebagai contoh, klasifikasi ruang kolaborasi sejalan dengan temuan (Kristensen, 2004) bahwa proses kreatif melibatkan proses kognitif secara kolaboratif.

Ruang kreatif ini terkait dengan penyediaan fasilitas yang memungkinkan berkembangnya ekosistem untuk inovasi berbasis pengetahuan tertentu (Ekomadyo, Santri, \& Riyadi, 2018). Beberapa penelitian mencoba mengungkap peran Ruang Pengetahuan dan Inovasi / Knowledge \& Innovation Space (KIS) dalam suatu kota. (Pancholi, et al (2015) menyebut bahwa keberadaan KIS ditentukan oleh empat aspek, yakni firm, management, people, dan space. Empat aspek inilah yang merupakan konteks pendukung dari KIS, juga ruang kreatif. Sebagai contoh, visi pemrakarsa dan koordinasi antar aktor berperan besar dalam menentukan arah pengembangan KIS. Sementara Oksanen \& Ståhle (2013) membuktikan adanya keterkaitan antara lingkungan fisik, kreativitas, dan inovasi.

Kota Bandung adalah salah satu contoh kota kreatif. Herawati, Rudatin, \& Akbar (2014) menyatakan bahwa pada saat itu, sektor industri kreatif di Bandung mampu menyerap kurang lebih 334.244 tenaga kerja dan menyumbang kontribusi $11 \%$ terhadap pertumbuhan ekonomi kota. Salah satu agenda kunci dalam perkembangan industri kreatif di Bandung adalah diresmikannya Bandung Creative City Forum di tahun 2008 oleh 50 organisasi kreatif, sebagai wadah kolaborasi antara pemerintah, industri, dan sektor kreatif (Siregar \& Sudrajat, 2017). Sejak saat itu, berbagai macam ruang kreatif mulai bermunculan di kota Bandung.

Penelitian ini bertujuan memetakan tipe-tipe ruang kreatif di Kota Bandung beserta hubungan dengan konteksnya melalui tiga studi kasus. Ketiga kasus yang dipilih adalah Kompleks Gudang Selatan (KGS), Lo.Ka.Si Coffee \& Space (Lo.Ka.Si), dan Bandung Creative Hub $(\mathrm{BCH})$; yang masing-masing memiliki konteks berbeda dalam hal pemrakarsa dan lokasi. KGS merupakan contoh kasus yang diprakarsai oleh perorangan dan terletak di kawasan bekas Gudang. Lo.Ka.Si diprakarsai oleh swasta dengan kolaborasi bersama Co-Working Indonesia dan terletak di kawasan komersil sekitar institusi-institusi pendidikan. Sedangkan, $\mathrm{BCH}$ diprakarsai oleh Dinas Kebudayaan dan Pariwisata dan terletak di lahan milik pemerintah di dekat pusat kota. Perbedaan ini diduga akan mempengaruhi tipe ruang kreatif yang tersedia di ketiga kasus. Harapannya, penelitian ini akan menghasilkan wawasan dan temuan pola yang dapat dimanfaatkan baik untuk pengembangan ruang kreatif di Kota Bandung.

\section{METODE PENELITIAN}

Penelitian ini bersifat kuantitatif dan kualitatif. Peneliti mengonversi prinsip desain dari Thoring, et al (2018) menjadi berbagai indikator dan melakukan pemetaan tipe ruang kreatif secara kuantitatif. Indikator tersebut kemudian diklasifikasi menjadi 5 kategori. Kategori pertama adalah knowledge repository yang merupakan kemampuan suatu ruang untuk menyediakan informasi yang mudah diakses. Kategori kedua adalah indicator of culture, yakni kemampuan tiap ruang-ruangnya untuk memenuhi tuntutan kegiatan. Kategori ketiga adalah process manifestation, yakni kemampuan ruang-ruangnya untuk mengarahkan pengguna dalam berkegiatan. Kategori keempat adalah social dimension, yakni bagaimana berbagai ruangnya menciptakan interaksi sosial. Kategori terakhir adalah source of stimulation yang merupakan kemampuan ruang untuk memantik ide/inovasi penggunanya. Selain itu peneliti juga memetakan secara kualitatif pada ketiga kasus berdasarkan interpretasi, yaitu penamaan ruang, anggapan pengelola dan pengguna, serta observasi. Bersamaan dengan itu, peneliti melakukan wawancara pengelola dan studi pustaka untuk menggali informasi mengenai konteks dari ketiga kasus. Data yang diperoleh akan dianalisis lalu dirumuskan sebagai temuan. Kerangka kerja penelitian ini diuraikan pada gambar 1.

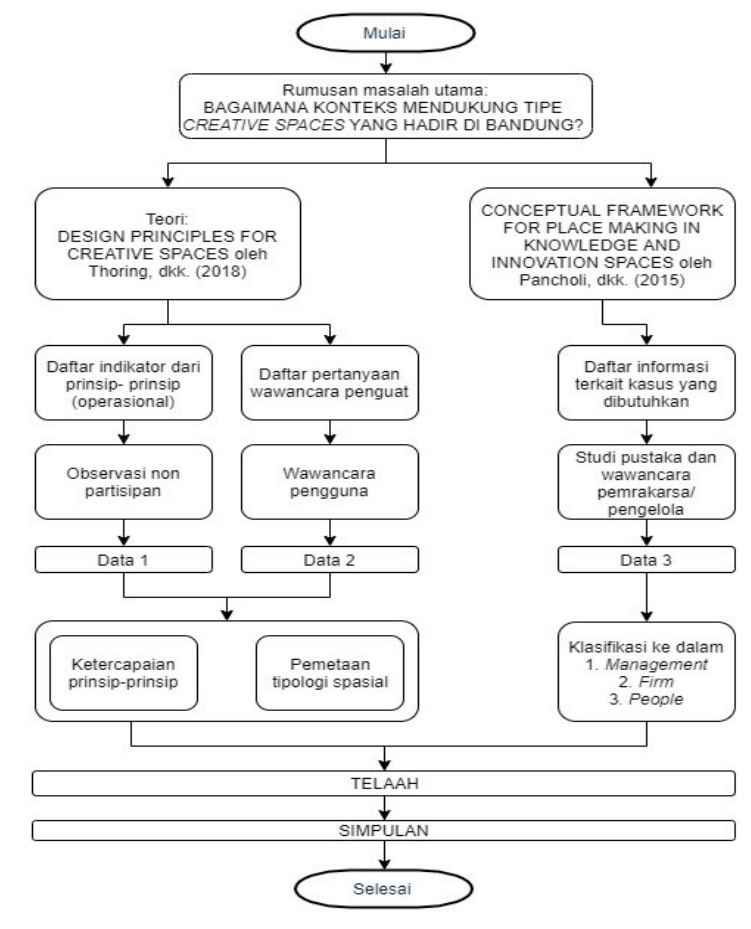


Gambar 1. Kerangka Kerja Penelitian (sumber: olahan peneliti, 2019)

\section{HASIL DAN PEMBAHASAN}

\subsection{Tipe Ruang Kreatif}

Hasil pemetaan tipe ruang kreatif secara kualitatif ditampilkan melalui denah lantai tiap kasus dan fotofoto. Lalu, hasil pemetaan secara kuantitatif ditampilkan melalui angka ketercapaian indikator. Pada tabel 1 terlihat matriks indikator beserta angka ketercapaian dari masing-masing kasus. Rentang angka ketercapaian merupakan skala angka senilai 03. Angka 0 mengindikasikan indikator fisik tidak tersedia sama sekali. Angka 1 menunjukkan tersedianya indikator fisik seadanya, namun tidak dipakai. Kemudian, angka 2 mengindikasikan terpakainya indikator fisik, namun kualitas kurang baik. Terakhir, angka 3 menunjukkan termanfaatkannya indikator fisik dengan kualitas yang baik.

Tabel 1. Indikator fisik tipe ruang kreatif

\begin{tabular}{|c|c|c|c|c|c|}
\hline \multirow{2}{*}{$\begin{array}{l}\text { Jenis } \\
\text { ruangan }\end{array}$} & \multirow{2}{*}{ Indikator Umum } & \multirow{2}{*}{ Indikator Fisik } & \multicolumn{3}{|c|}{ Ketercapaian } \\
\hline & & & KGS & LKS & $\mathrm{BCH}$ \\
\hline \multirow{7}{*}{$\begin{array}{l}\text { Personal } \\
\text { Space }\end{array}$} & \multirow[t]{3}{*}{ Knowledge Processor } & Merupakan ruang individu & 3 & 3 & 3 \\
\hline & & Terdapat perpustakaan/buku-buku & 0 & 0 & 2 \\
\hline & & Terdapat akses internet & 1 & 2 & 2 \\
\hline & Indicator of Culture & Merupakan ruang bersekat & 3 & 0 & 3 \\
\hline & Process Enabler & Terdapat titik listrik yang dapat digunakan & 3 & 3 & 3 \\
\hline & Social Dimension & Dapat berupa lebih dari 1 macam ruang & 0 & 0 & 0 \\
\hline & Source of Stimulation & Terletak jauh/ terjaga dari keramaian & 3 & 2 & 3 \\
\hline \multirow{9}{*}{$\begin{array}{l}\text { Collaboration } \\
\text { Space }\end{array}$} & Knowledge Processor & Terdapat pertukaran informasi & 3 & 3 & 3 \\
\hline & \multirow[t]{2}{*}{ Indicator of Culture } & Merupakan ruang komunal & 1 & 3 & 2 \\
\hline & & Terdapat petunjuk penggunaan ruang & 0 & 3 & 2 \\
\hline & \multirow[t]{2}{*}{ Process Enabler } & $\begin{array}{l}\text { Merupakan ruangan dengan layout ruang dan furnitur } \\
\text { fleksibel }\end{array}$ & 3 & 3 & 3 \\
\hline & & Terdapat jadwal/ mekanisme penyewaan ruang & 3 & 3 & 3 \\
\hline & \multirow[t]{2}{*}{ Social Dimension } & Terdapat meeting area & 1 & 3 & 2 \\
\hline & & Layout furnitur untuk mengobrol/ kolaborasi & 2 & 3 & 2 \\
\hline & \multirow[t]{2}{*}{ Source of Stimulation } & Terdapat peralatan audio-visual & 3 & 3 & 3 \\
\hline & & Terdapat soundproofing & 0 & 2 & 3 \\
\hline \multirow[t]{6}{*}{ Maker Space } & Knowledge Processor & Terdapat contoh fisik hasil pengetahuan & 1 & 0 & 0 \\
\hline & \multirow[t]{2}{*}{ Indicator of Culture } & Terdapat bengkel & 1 & 1 & 3 \\
\hline & & Terdapat peralatan untuk bengkel & 1 & 1 & 3 \\
\hline & \multirow[t]{2}{*}{ Process Enabler } & Terdapat material dan bahan & 1 & 0 & 0 \\
\hline & & Merupakan ruangan yang cukup luas & 1 & 2 & 3 \\
\hline & Social Dimension & $\begin{array}{l}\text { Terdapat barier/jarak agar keramaian dari dalam ruangan } \\
\text { tidak mengganggu sekitarnya }\end{array}$ & 0 & 3 & 3 \\
\hline \multirow{5}{*}{$\begin{array}{l}\text { Presentasion } \\
\text { Space }\end{array}$} & Knowledge Processor & Merupakan ruang komunal & 2 & 3 & 3 \\
\hline & Source of Stimulation & Terdapat tempat untuk audiens & 1 & 3 & 3 \\
\hline & Process Enabler & Terdapat peralatan presentasi & 3 & 3 & 3 \\
\hline & Social Dimension & $\begin{array}{l}\text { Layout memungkinkan interaksi antara audiens dan } \\
\text { presenter }\end{array}$ & 2 & 3 & 2 \\
\hline & Source of Stimulation & Terletak jauh/ terjaga dari keramaian & 3 & 3 & 3 \\
\hline \multirow[t]{8}{*}{$\begin{array}{l}\text { Intermission } \\
\text { Space }\end{array}$} & Knowledge Processor & $\begin{array}{l}\text { Terdapat taman yang bersifat publik (bisa diakses } \\
\text { masyarakat luar) }\end{array}$ & 0 & 0 & 2 \\
\hline & Indicator of Culture & Terdapat lounge / pantry area dengan fungsi sejenis & 1 & 3 & 0 \\
\hline & Process Enabler & $\begin{array}{l}\text { Terdapat furnitur / wujud fisik untuk berkumpul dan } \\
\text { berinteraksi secara informal }\end{array}$ & 3 & 3 & 3 \\
\hline & Social Dimension & Terdapat toko/akses ke supplier untuk kegiatan kreatif & 0 & 0 & 0 \\
\hline & \multirow[t]{4}{*}{ Source of Stimulation } & Terdapat area terbuka & 3 & 3 & 3 \\
\hline & & Terdapat kantin / warung / area dengan fungsi sejenis & 1 & 3 & 0 \\
\hline & & Terdapat area hijau (tanaman, rumput) & 3 & 3 & 3 \\
\hline & & Terdapat elemen alami (air, bebatuan) & 1 & 3 & 3 \\
\hline
\end{tabular}

Sumber: hasil analisis, 2019 


\section{Tipe Ruang Kreatif Komplek Gudang Selatan (KGS)}

Pemetaan ruang kreatif pada Komplek Gudang Selatan terlihat pada gambar 2, 3, 4, 5 dan 6 berikut

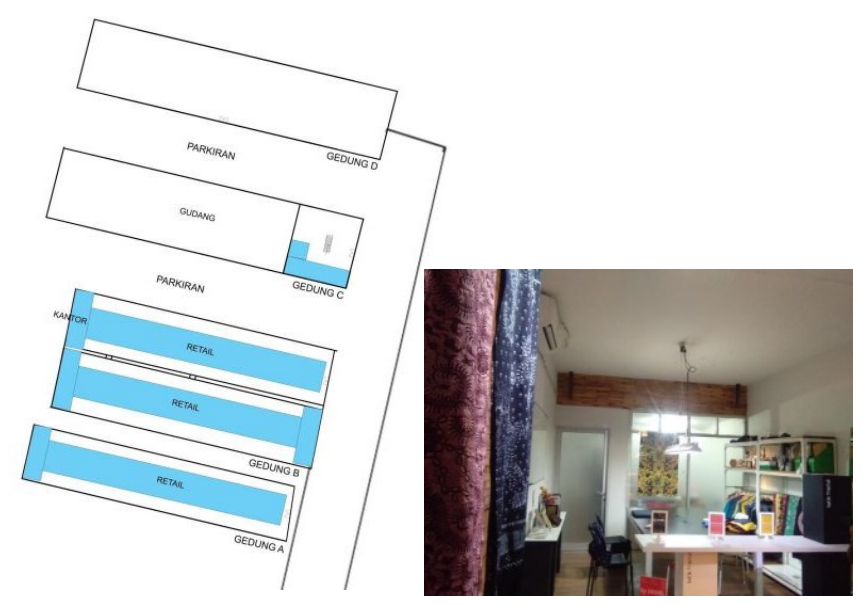

Gambar 2. Ruang personal KGS dan suasana ruang personal di KGS (sumber: analisis dan dokumentasi peneliti, 2019)

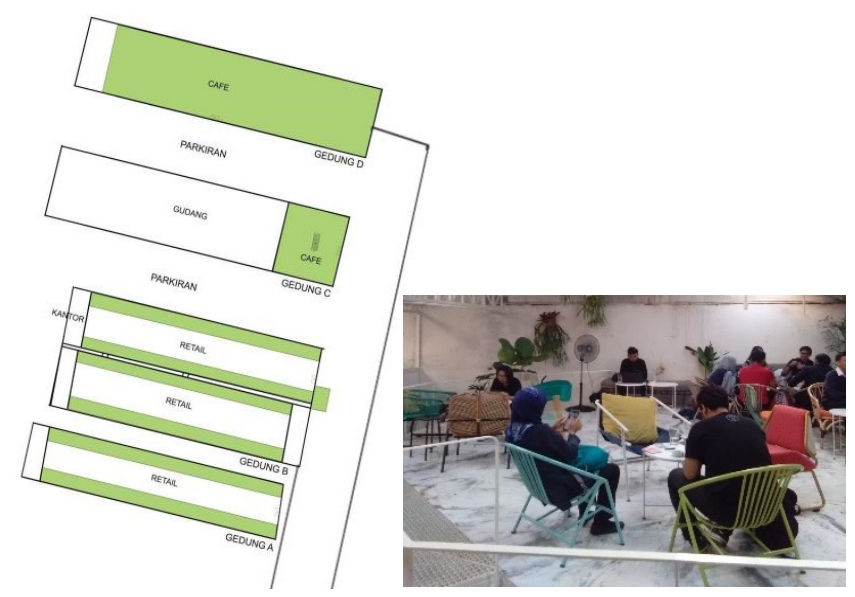

Gambar 3. Ruang kolaborasi KGS dan suasana ruang kolaborasi di KGS (sumber: analisis dan dokumentasi peneliti, 2019)

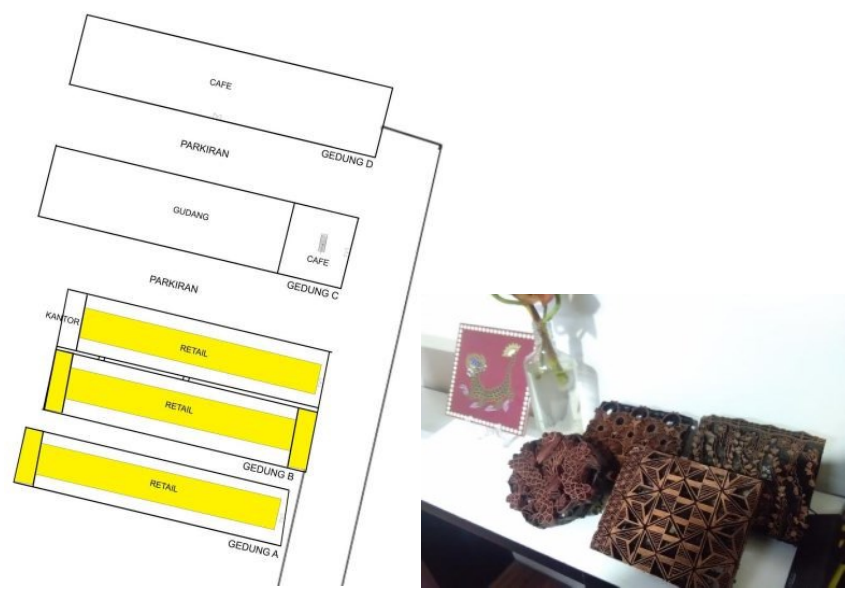

Gambar 4. Ruang cipta KGS dan contoh alat cipta di KGS (sumber: analisis dan dokumentasi peneliti, 2019)

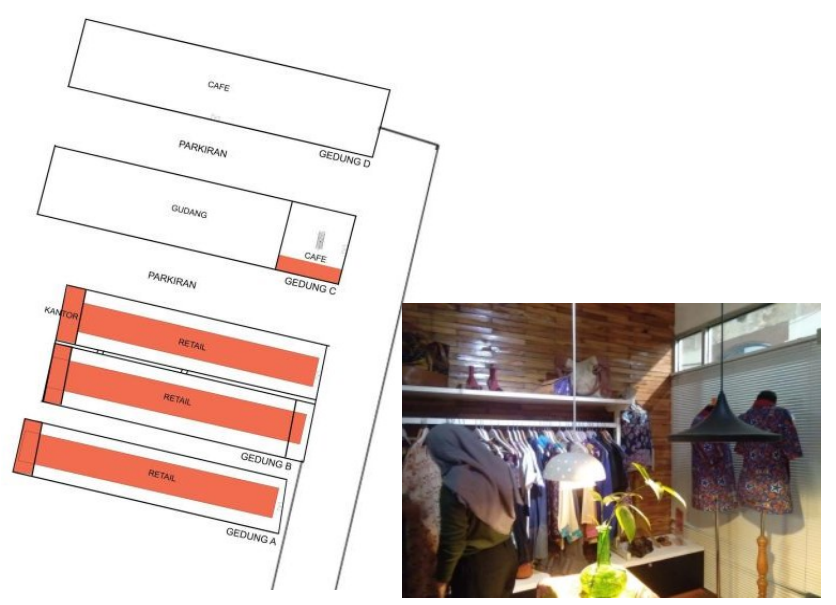

Gambar 5. Ruang presentasi KGS dan suasana ruang presentasi di KGS (sumber: analisis dan dokumentasi peneliti, 2019)

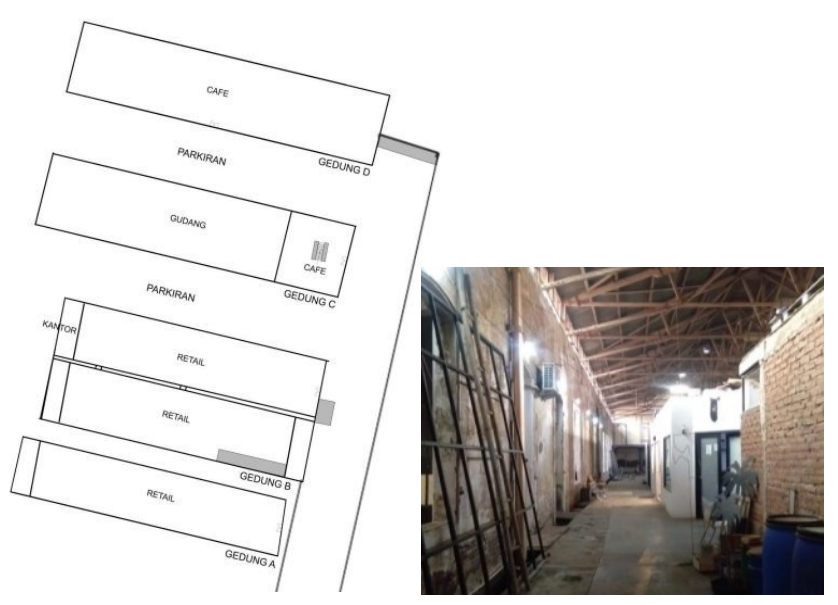

Gambar 6. Ruang perantara KGS dan suasana ruang perantara di KGS (sumber: analisis dan dokumentasi peneliti, 2019)

Berdasarkan hasil pemetaan, memperlihatkan tipe ruang kreatif yang paling banyak diakomodasi oleh KGS adalah ruang presentasi. Kemudian disusul dengan ruang kolaborasi, ruang cipta, ruang personal, dan ruang perantara pada posisi terakhir. Hasil pemetaan ini didukung dengan angka ketercapaian indikator ruang presentasi yang mencapai $73 \%$ (lihat tabel 2)

Tabel 2. Persentase skor ketercapaian indikator ruang kreatif di KGS

\begin{tabular}{ll}
\hline Tipe Ruang Kreatif & Skor \\
\hline Ruang Personal & $61,90 \%$ \\
Ruang Kolaborasi & $59,26 \%$ \\
Ruang Cipta & $27,78 \%$ \\
Ruang Presentasi & $73,33 \%$ \\
Ruang Perantara & $66,67 \%$ \\
\hline
\end{tabular}


Sumber: hasil analisis, 2019

Tipe Ruang Kreatif Lo.Ka.Si Coffe \& Space

Pemetaan ruang kreatif pada Lo.Ka.Si Coffe \& Space terlihat pada gambar 7, 8, 9, 10 dan 11 berikut

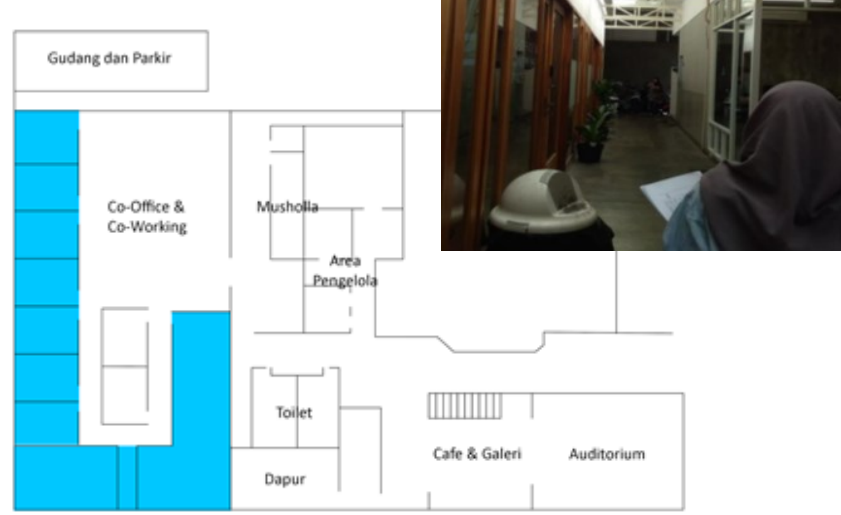

Gambar 7. Ruang personal Lo.Ka.Si dan suasana ruang personal di Lo.Ka.Si (sumber: analisis dan dokumentasi peneliti, 2019)

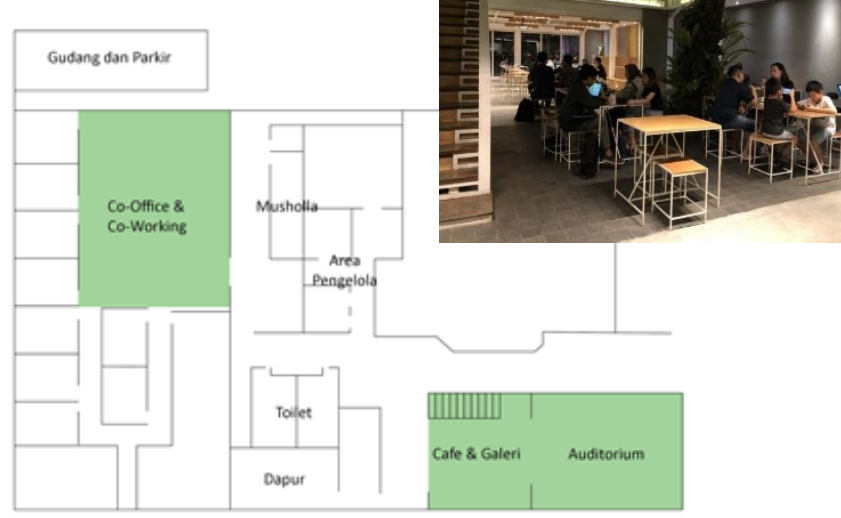

Gambar 8. Ruang kolaborasi Lo.Ka.Si dan suasana ruang kolaborasi di Lo.Ka.Si (sumber: analisis dan dokumentasi peneliti, 2019)

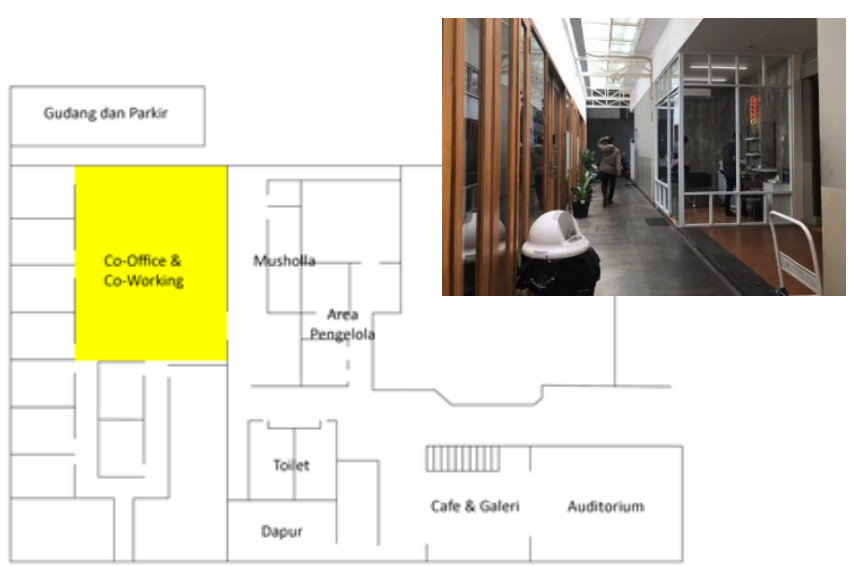

Gambar 9. Ruang cipta Lo.Ka.Si dan suasana ruang cipta di Lo.Ka.Si (sumber: analisis dan dokumentasi peneliti, 2019)

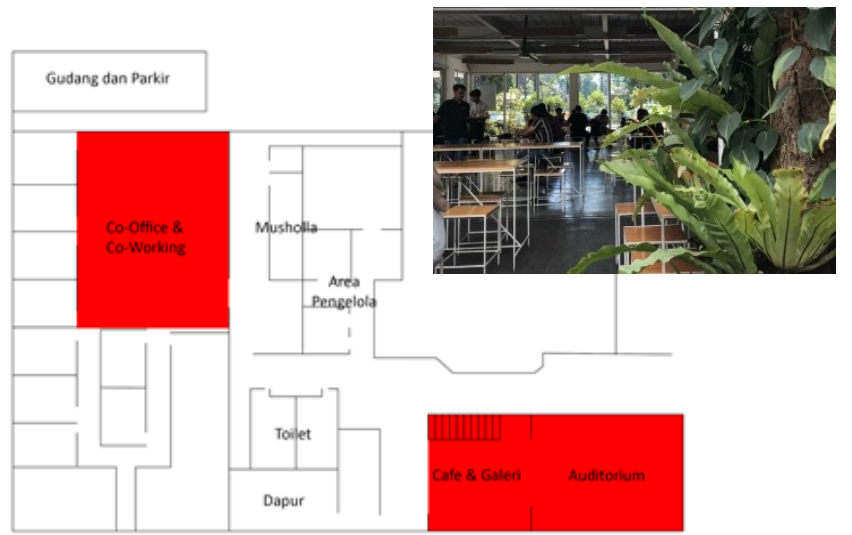

Gambar 10. Ruang presentasi Lo.Ka.Si dan suasana ruang presentasi di Lo.Ka.Si (sumber: analisis dan dokumentasi peneliti, 2019)

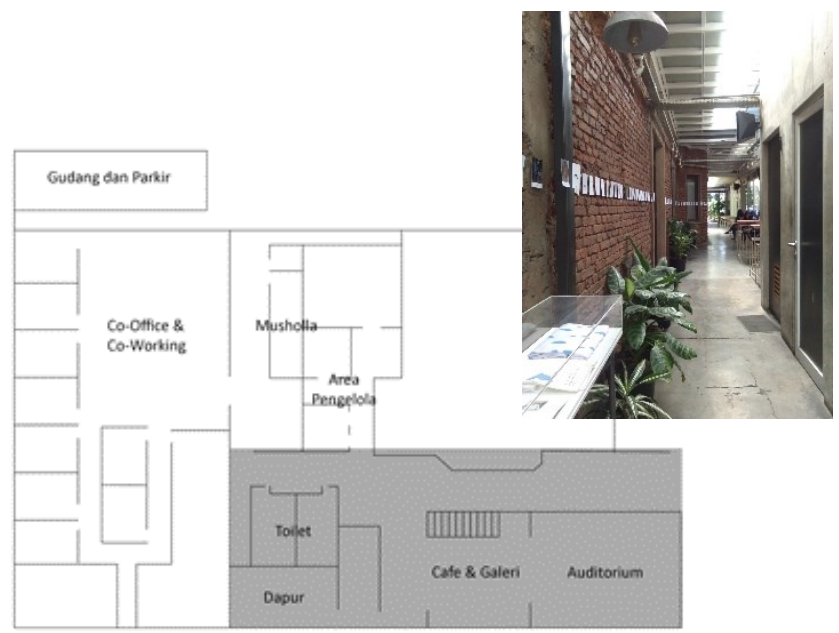

Gambar 11. Ruang perantara Lo.Ka.Si dan suasana ruang perantara di Lo.Ka.Si (sumber: analisis dan dokumentasi peneliti, 2019)

Berdasarkan hasil pemetaan, terlihat bahwa tipe ruang kreatif yang paling banyak diakomodasi oleh Lo.Ka.Si adalah ruang presentasi. Kemudian disusul dengan ruang kolaborasi, ruang perantara, ruang personal, dan ruang cipta pada posisi terakhir. Hasil pemetaan ini didukung dengan angka ketercapaian indikator ruang presentasi yang mencapai 100\% (lihat tabel 3).

Tabel 3. Persentase skor ketercapaian indikator ruang kreatif di Lo.Ka.Si

\begin{tabular}{ll}
\hline Tipe Ruang Kreatif & Skor \\
\hline Ruang Personal & $47,61 \%$ \\
Ruang Kolaborasi & $96,29 \%$ \\
Ruang Cipta & $38,88 \%$ \\
Ruang Presentasi & $100,00 \%$
\end{tabular}




\section{Ruang Perantara $\quad 75,00 \%$}

Sumber: hasil analisis, 2019

\section{Tipe Ruang Kreatif Bandung Creative Hub (BCH)}

Pemetaan ruang kreatif pada Bandung Creative Hub terlihat pada gambar $12,13,14,15$ dan 16 berikut

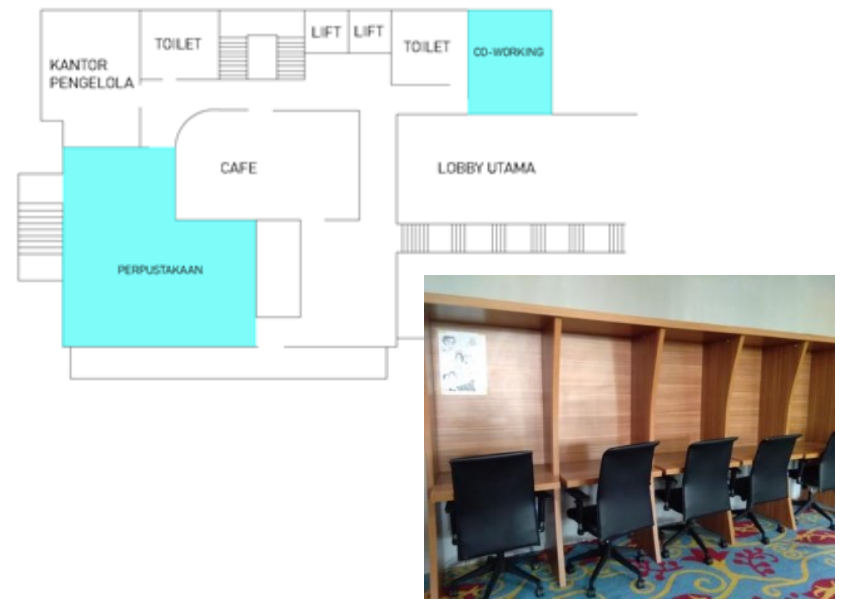

Gambar 12. Ruang personal BCH dan suasana ruang personal di $\mathrm{BCH}$ (sumber: analisis dan dokumentasi peneliti, 2019)

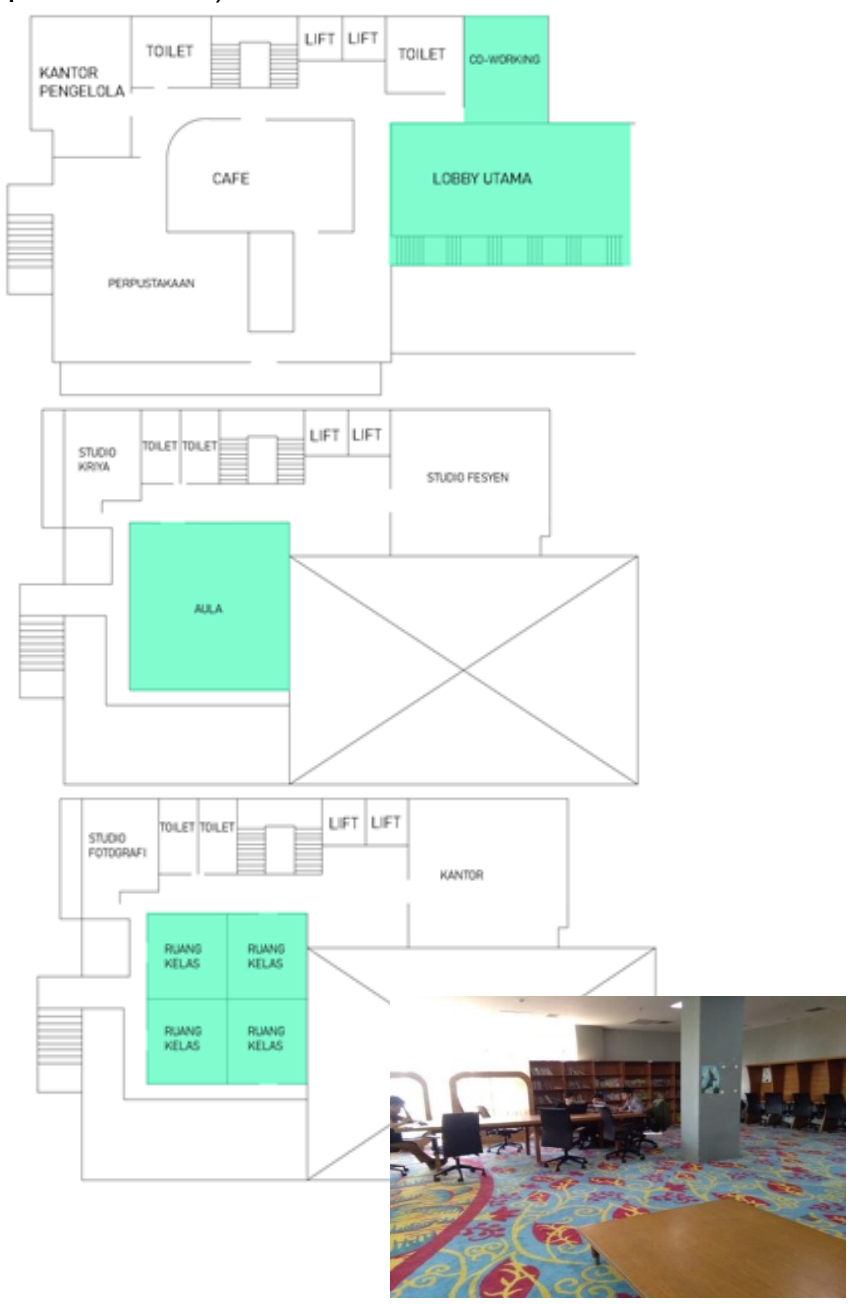

Gambar 13. Ruang kolaborasi $\mathrm{BCH}$ dan suasana ruang kolaborasi di $\mathrm{BCH}$ (sumber: analisis dan dokumentasi peneliti, 2019)

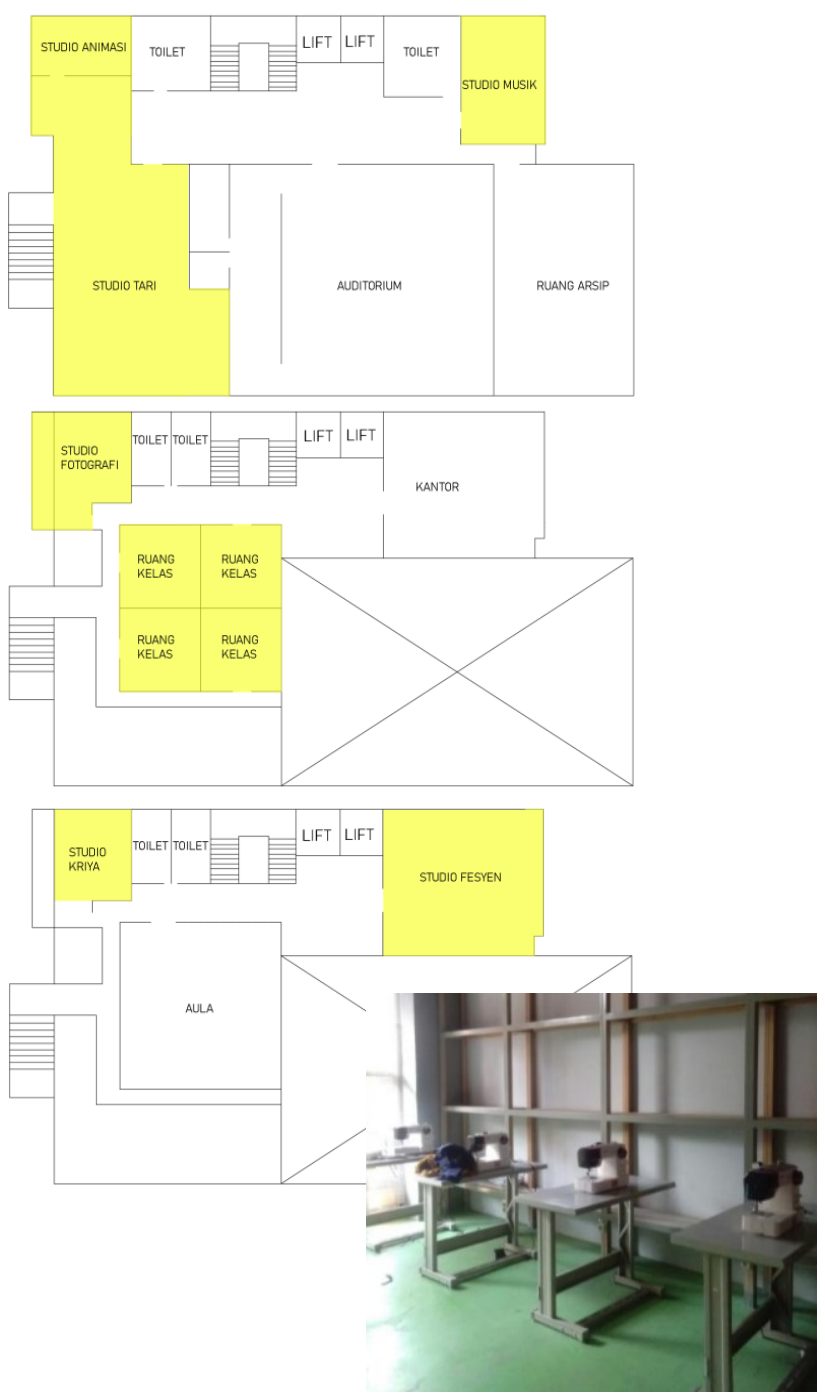

Gambar 14. Ruang cipta BCH dan suasana ruang cipta di $\mathrm{BCH}$ (sumber: analisis dan dokumentasi peneliti, 2019)

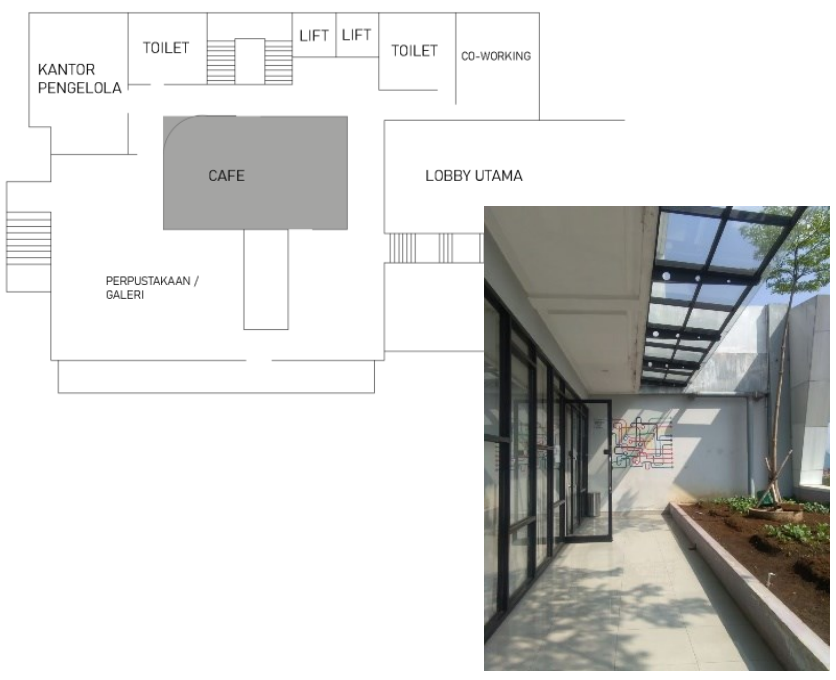


Gambar 15. Ruang perantara BCH dan suasana ruang perantara di $\mathrm{BCH}$ (sumber: analisis dan dokumentasi peneliti, 2019

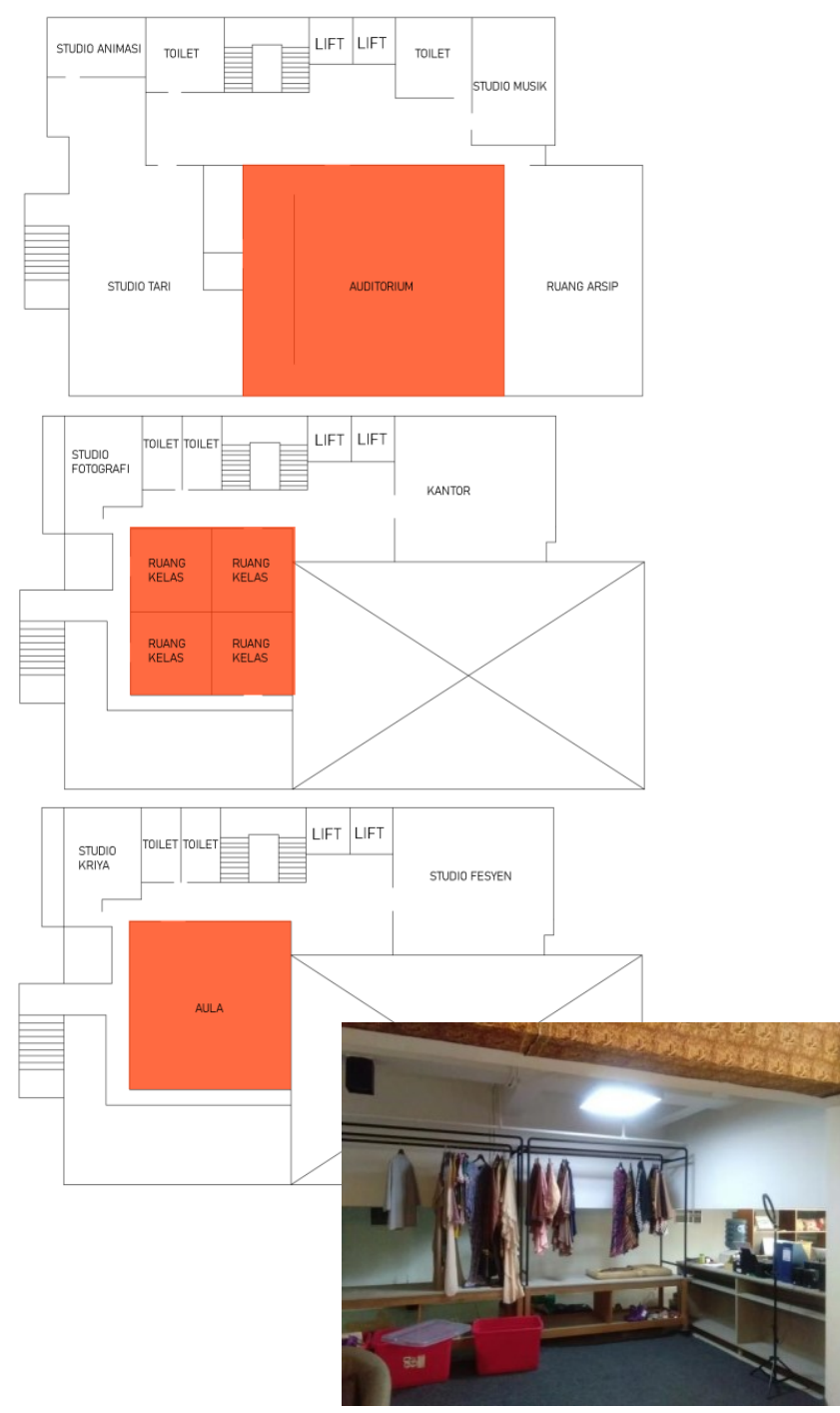

Gambar 16. Ruang presentasi $\mathrm{BCH}$ dan suasana ruang presentasi di $\mathrm{BCH}$ (sumber: analisis dan dokumentasi peneliti, 2019

Berdasarkan hasil pemetaan diatas, terlihat bahwa tipe ruang kreatif yang paling banyak diakomodasi oleh $\mathrm{BCH}$ adalah ruang presentasi. Kemudian disusul dengan ruang cipta, ruang kolaborasi, ruang personal, dan ruang perantara pada posisi terakhir. Hasil pemetaan ini didukung dengan angka ketercapaian indikator ruang presentasi yang mencapai 93\%.(lihat tabel 4).

Tabel 4. Persentase skor ketercapaian indikator ruang kreatif di $\mathrm{BCH}$

\begin{tabular}{ll}
\hline Tipe Ruang Kreatif & Skor \\
\hline Ruang Personal & $76,19 \%$ \\
Ruang Kolaborasi & $85,18 \%$ \\
Ruang Cipta & $66,67 \%$
\end{tabular}
Ruang Presentasi
$93,33 \%$
Ruang Perantara
$58,33 \%$

Sumber: hasil analisis, 2019

\subsection{Konteks Ruang Kreatif \\ Konteks Komplek Gudang Selatan}

Management dalam kasus ini dirintis dan dimiliki secara pribadi oleh pemrakarsa yang berprofesi sebagai pengusaha. Pendanaan awal berasal dari dana pribadi, tanpa hibah dari pemerintah maupun institusi lainnya. Kini KGS ini dikelola langsung oleh para pemilik secara informal tanpa berkolaborasi dengan pihak eksternal. Pengembangan KGS bukan hanya berfokus pada keuntungan pribadi namun lebih kepada mewadahi dan mendorong para perintis bisnis.

Untuk aspek firm, tidak ada pembatasan jenis usaha pada tennant yang disewakan, namun semua penyewa tenant merupakan usaha di bidang industri kreatif mulai dari fashion, kerajinan, desain, hingga kafe. Kafe dan beberapa merk fashion tersebut menjadi daya tarik dari tempat ini. Di antara para pemilik usaha di sana tidak ada komunitas resmi yang mengikat sehingga diskusi dan kolaborasi diantaranya terjadi secara informal di ruang-ruang komunal yang disediakan.

Dalam hal people banyaknya usaha di bidang industri kreatif yang bertempat di kompleks ini mau tak mau membuat pelaku industri kreatif menjadi kelompok yang dominan beraktivitas di KGS ini. Bangunannya yang merupakan bekas gudang mampu menarik perhatian individu maupun kelompok dengan karakter tertentu seperti penikmat sejarah dan penikmat seni. Selain itu, kehadiran beberapa toko kopi menjadi poin pelengkap sehingga KGS ini sangat diminati para muda-mudi industri kreatif.

\section{Konteks Lo.Ka.Si Coffe \& Space}

Management dalam studi kasus ini dirintis oleh pihak swasta lewat kerjasama dengan komunitas Coworking Indonesia. Atmosfer manajemen Lo.Ka.Si cukup santai dan fleksibel, sesuai dengan karakter tempat kreatif. Hal ini memudahkan pihak manajemen dalam berinteraksi dengan pengguna, juga calon kolaborator. Lo.Ka.Si mempunyai media sosial yang cukup aktif sehingga memiliki jaringan yang luas.

Untuk aspek firm, Lo.Ka.Si memiliki co-working area, dimana pemrakarsanya bekerjasama dengan Coworking Indonesia. Coworking area ini dapat dimanfaatkan oleh berbagai kalangan, tanpa dibatasi jenisnya. Hal ini menguntungkan orang-orang di sekitar Lo.Ka.Si yang mayoritas adalah mahasiswa dan pekerja pada perusahaan startup, dimana mereka membutuhkan ruang untuk bekerja dan berkolaborasi.

Dalam hal people, pengguna Lo.Ka.Si didominasi oleh mahasiswa dan kalangan muda, dikarenakan letaknya yang dekat dengan Kampus Institut Teknologi 
Bandung, perusahaan startup bukalapak, SMAN 1 Bandung, dan sebagainya. Tenant yang menempati Lo.Ka.Si juga cenderung mengarah ke fashion dan seni yang banyak digandrungi kalangan muda

\section{Konteks Bandung Creative Hub}

Management dalam kasus Bandung Creative Hub diprakarsai oleh Walikota Bandung saat itu, M. Ridwan Kamil dan Wakil Wali Kota Bandung Oded M. Danial pada tahun 2017. Bangunan ini bertujuan untuk untuk mewadahi aktivitas komunitas kreatif di Bandung, mengembangkan edukasi, dan menjadi pusat kegiatan kreatif. $\mathrm{BCH}$ sekarang berada dibawah pengelolaan Dinas Kebudayaan dan Pariwisata (Disbudpar) Kota Bandung.

Untuk aspek firm, BCH bekerjasama dengan pihak Disbudpar kota Bandung termasuk dalam manajemen konten kegiatan yang diwadahi. Ruang-ruang di dalam bangunan dibatasi melalui dinding dan zonasi vertikal. Ruang-ruang presentasi ditempatkan di bagian lantai dasar yang bersifat lebih publik, sedangkan ruang kolaborasi dan ruang cipta ditempatkan di lantai-lantai yang lebih atas untuk menjaga privasi ruang.

Sedangkan dalam hal people, komunitas yang mengunjungi $\mathrm{BCH}$ secara umum berasal dari segala kalangan masyarakat Bandung, namun berdasarkan fasilitas yang disediakan yang terdiri dari wadah untuk membuat dan memamerkan karya, $\mathrm{BCH}$ cenderung lebih menarik minat anak muda dan orang dewasa yang produktif terutama dalam bidang kreatif.

\subsection{Perbandingan Ruang Kreatif dan Konteks pada ke tiga kasus}

Untuk memperoleh gambaran dari ketiga objek penelitian terkait skor penilaian tipe ruang kreatif dan konteksnya masing-masing, maka pada tabel 5 dan 6 dapat terlihat tabulasi perbandingan dari ke tiga studi kasus.

Tabel 5. Perbandingan capaian persentase skor indikator pada ke tiga kasus amatan.

\begin{tabular}{lccc}
\hline $\begin{array}{l}\text { Tipe Ruang } \\
\text { Kreatif }\end{array}$ & KGS & Lo.Ka.Si & BCH \\
\hline Ruang Personal & $61,90 \%$ & $47,61 \%$ & $76,19 \%$ \\
Ruang Kolaborasi & $59,26 \%$ & $96,29 \%$ & $85,18 \%$ \\
Ruang Cipta & $27,78 \%$ & $38,88 \%$ & $66,67 \%$ \\
Ruang Presentasi & $73,33 \%$ & $100,00 \%$ & $93,33 \%$ \\
Ruang Perantara & $66,67 \%$ & $75,00 \%$ & $58,33 \%$ \\
\hline
\end{tabular}

Sumber: hasil analisis, 2019

Dari perbandingan pada tabel 5 diketahui bahwa ruang presentasi menjadi tipe ruang yang paling dominan pada setiap objek amatan. Ruang presentasi pada Kompleks Gudang Selatan muncul karena kebutuhan para tenant yang sebagian besar merupakan pengusahaidan kerajinan. Pada kasus ini, ruang presentasi yang tersedia berupa bagian dari masing-masing bilik tenant yang difungsikan untuk memasarkan produk / karyanya. Para penyewa mempresentasikan produknya dalam bentuk display dengan tema tertentu. Pada kasus Lo.Ka.Si Coffee \& Space, pengadaan ruang presentasi merupakan perwujudan dari tagline pendirinya, yaitu eat-connectshare, yang berusaha menghadirkan ruang-ruang bagi penggunanya untuk dapat berkolaborasi dan berbagi. Ruang-ruang ini sering digunakan oleh kolaborator baik untuk mempresentasikan produk/ karya, juga untuk event. Bandung Creative Hub menyediakan ruang presentasi sebagai perwujudan tugas Disbudpar dalam mendongkrak pariwisata di Bandung, terutama lewat budaya dan produk kreatif. Hal ini menuntut $\mathrm{BCH}$ untuk menyediakan ruang-ruang ciptanya sekaligus sebagai galeri / ruang presentasi. Kegiatan-kegiatan yang banyak berlangsung di $\mathrm{BCH}$ juga mengarah ke pameran dan eksibisi. Perbandingan konteks antara ke tiga lokasi amatan dapat terlihat pada tabel 6 .

Tabel 6. Perbandingan konteks pada ke tiga kasus amatan

\begin{tabular}{|c|c|c|c|}
\hline & Management & Firm & People \\
\hline $\begin{array}{l}\mathscr{C} \\
\mathbb{1}\end{array}$ & $\begin{array}{l}\text { Dirintis dan } \\
\text { dikelola oleh } \\
\text { pemrakarsa } \\
\text { yang berprofesi } \\
\text { sebagai } \\
\text { pengusaha }\end{array}$ & $\begin{array}{l}\text { Tenant banyak } \\
\text { digunakan oleh } \\
\text { perintis usaha } \\
\text { di industri } \\
\text { kreatif }\end{array}$ & $\begin{array}{l}\text { Pengguna dalah } \\
\text { para perintis } \\
\text { usaha di industri } \\
\text { kreatif dan } \\
\text { konsumennya }\end{array}$ \\
\hline "̄ & $\begin{array}{l}\text { Diprakarsai dan } \\
\text { dikelola oleh } \\
\text { swasta } \\
\text { bersama } \\
\text { Coworking } \\
\text { Indonesia }\end{array}$ & $\begin{array}{l}\text { Banyak } \\
\text { digunakan oleh } \\
\text { kolaborator } \\
\text { berupa institusi } \\
\text { kecil dan } \\
\text { startup untuk } \\
\text { sosialisasi/ } \\
\text { event }\end{array}$ & $\begin{array}{l}\text { Pelaku mayoritas } \\
\text { adalah } \\
\text { mahasiswa dari } \\
\text { institusi } \\
\text { Pendidikan } \\
\text { disekitar, siswa } \\
\text { sekolah, dan } \\
\text { pekerja }\end{array}$ \\
\hline I & $\begin{array}{l}\text { Diprakarsai } \\
\text { oleh walikota } \\
\text { dan dikelola } \\
\text { oleh Disbudpar }\end{array}$ & $\begin{array}{l}\text { Disbudpar } \\
\text { berwenang } \\
\text { dominan dalam } \\
\text { pengadaan dan } \\
\text { perizinan } \\
\text { kegiatan, juga } \\
\text { pemanfaatan } \\
\text { fasilitas di } \\
\text { dalam } \mathrm{BCH}\end{array}$ & $\begin{array}{l}\text { Diperuntukkan } \\
\text { untuk umum, } \\
\text { namun } \\
\text { cenderung } \\
\text { digunakan oleh } \\
\text { anak muda dan } \\
\text { dewasa yang } \\
\text { berkepentingan } \\
\text { di bidang kreatif }\end{array}$ \\
\hline
\end{tabular}

Sumber: hasil analisis, 2019

Terkait ruang presentasi yang menjadi tipe ruang yang dominan, tak lepas dari kehadiran faktor pendukung yang mendukung hal tersebut terjadi (lihat tabel 7).

Tabel 7. Faktor pendukung keberadaan ruang presentasi pada masing-masing kasus

\begin{tabular}{ll}
\hline Kasus & Faktor pendukung \\
\hline KGS & $\begin{array}{l}\text { Tenant yang dominan berupa usaha } \\
\text { clothing dan kerajinan kreatif }\end{array}$
\end{tabular}

Lo.Ka.Si Kerjasama dengan Coworking Indonesia dengan kolaborator yang banyak mengadakan event 
$\mathrm{BCH}$ Dinas Kebudayaan dan Pariwisata sebagai instansi pemerintah yang berwenang di $\mathrm{BCH}$

Sumber: hasil analisis, 2019

Temuan-temuan tersebut menunjukkan bahwa ruang presentasi pada masing-masing kasus tersedia karena kepentingan berbagai pemegang kepentingan di dalamnya. Apabila dikategorikan kedalam aspekaspek konteks, pemegang kepentingan merupakan elemen-elemen dalam aspek firm. Sehingga dapat dikatakan bahwa aspek firm lah yang mendukung tersedianya ruang presentasi di ketiga kasus.

\section{KESIMPULAN}

Kompleks Gudang Selatan, Lo.Ka.Si Coffee \& Space, dan Bandung Creative Hub merupakan ruang kreatif yang ketiganya didominasi oleh tipe ruang presentasi. Hal ini didukung oleh masing-masing konteks mereka, terutama pada aspek firm. Meski demikian, kondisi aspek firm pada tiap kasus berbedabeda. Komplek Gudang Selatan memiliki ruang presentasi sebagai pemenuhan kebutuhan para tenant-nya, Lo.Ka.Si Coffee \& Space menyediakan ruang presentasi untuk para kolaboratornya. Sedangkan ruang presentasi di Bandung Creative Hub merupakan cerminan dari tujuan Disbudpar dalam pariwisata. Hal ini menunjukkan bahwa, ruang presentasi banyak disediakan pada ruang-ruang kreatif di Kota Bandung, sebagai bagian dari Knowledge Innovation Space (KIS). Penyediaan ini merupakan respon atas kebutuhan kegiatan dari berbagai kalangan pelakunya, baik pemerintah, swasta, maupun masyarakat. Di sisi lain, presentasi bukanlah satu-satunya kegiatan yang perlu diwadahi di dalam ruang kreatif. Terdapat banyak kegiatan lain yang belum terwadahi dalam bentuk wujud ruangan di ketiga kasus. Hal ini mengindikasikan bahwa industri kreatif di Bandung masih berorientasi pada kegiatan presentasi saja, sehingga cenderung mengutamakan impresi.

\section{DAFTAR PUSTAKA}

Ekomadyo, A. S., Santri, T., \& Riyadi, A. (2018). Habitat for Innovative Milieu: A Place-Making Study of University and Start-up Enterprises Relationship. IOP Conference Series: Earth and Environmental Science, 152, 012020 . doi: 10.1088/1755-1315/152/1/012020

Florida, R. (2014). The Rise of the Creative Class-Revisited: Revised and Expanded. New York: Hachette UK.

Herawati, T., Rudatin, C. L. T., \& Akbar, D. (2014). Potensi Kota Bandung Sebagai Destinasi Incentive Melalui Pengembangan Ekonomi Kreatif. Epigram, 11(2), 95-102. doi: 10.32722/epi.v11i2.672
Kristensen, T. (2004). The Physical Context of Creativity. Creativity and Innovation Management, 13(2), 89-96. doi: 10.1111/j.09631690.2004.00297.x

Oksanen, K., \& Ståhle, P. (2013). Physical environment as a source for innovation: Investigating the attributes of innovative space. Journal of Knowledge Management, 17(6), 815-827. doi: 10.1108/JKM-04-2013-0136

Pancholi, S., Yigitcanlar, T., \& Guaralda, M. (2015). Place making facilitators of knowledge and innovation spaces: Insights from European best practices. International Journal of KnowledgeBased Development, 6(3), 215-240. doi: 10.1504/IJKBD.2015.072823

Siregar, F., \& Sudrajat, D. (2017). Enabling Spaces: Mapping Creative Hubs in Indonesia Fajri Siregar-Academia.edu (p. 54). Retrieved from Centre for Innovation Policy and Governance website: https://cipg.or.id/creative-hubs/

Thoring, K., Desmet, P., \& Badke-Schaub, P. (2019). Creative Space: A Systematic Review of the Literature. Proceedings of the 22nd International Conference on Engineering Design (ICED19), 1, 299-308. doi: 10.1017/dsi.2019.33

Thoring, K., Luippold, C., \& Ueller, R. M. M. (2012). Creative Space In Design Education: A Typology of Spatial Functions. Prosiding EPDE 2012, 6. Retrieved from https://www.designsociety.org/downloadpublication/33233/Creative+Space+in+Design+ Education\%3A+A+Typology+of+Spatial+Functi ons

Thoring, K., Mueller, R. M., Desmet, P., \& BadkeSchaub, P. (2018). Design Principles For Creative Spaces. Proceedings of the DESIGN 2018, 1969-1980. doi: 10.21278/idc.2018.0233 